\title{
Numerical Simulation Research on Cutting Rock with a PDC Cutter Assisted by an Impact Force
}

\author{
Yong Wang (D), Hongjian Ni $(\mathbb{D}$, Ruihe Wang, Bin Huang, Shubin Liu, and Heng Zhang \\ School of Petroleum Engineering, China University of Petroleum (East China), Qingdao 266580, China \\ Correspondence should be addressed to Hongjian Ni; nhj_upc@126.com
}

Received 29 October 2021; Revised 13 December 2021; Accepted 17 December 2021; Published 7 January 2022

Academic Editor: Guoming Liu

Copyright ( $\odot 2022$ Yong Wang et al. This is an open access article distributed under the Creative Commons Attribution License, which permits unrestricted use, distribution, and reproduction in any medium, provided the original work is properly cited.

\begin{abstract}
Extensive studies have been carried out on cutting rock with a PDC cutter, but cutting rock assisted by impact force is rarely studied. In this paper, cutting rock using conical and cylindrical PDC cutters assisted by impact force were researched with the explicit dynamic model. The laws of cutting rock using a cylindrical cutter assisted by impact force are the same as those of a conical cutter. There are thresholds of impact frequency and amplitude when they are single variables. When impact frequency is lower than the threshold frequency, the impact frequency is the dominant frequency in the frequency spectrum of weight on bit (WOB), and the amplitude of dominant frequency and removal volume decreases with the increase of impact frequency. When the impact frequency is higher than the threshold frequency, there is no dominant frequency in the frequency spectrum of WOB, and the removal volume behaves the same. When the impact force is lower than the threshold amplitude, there is no dominant frequency in the frequency spectrum of WOB, and it does not affect the removal volume but the removal volume is positively correlated with the impact amplitude. When the impact amplitude is higher than the threshold amplitude, the removal volume is also positively correlated with the impact amplitude, and the removal volume assisted by low-frequency $(20 \mathrm{~Hz}$ and $40 \mathrm{~Hz}) \mathrm{impact}$ force is higher. The frequency threshold and amplitude threshold of the conical cutter are smaller than those of the cylindrical cutter. Although the cutting depth and removal volume of the conical cutter are lower than those of the cylindrical cutter, the amplifications of cutting depth and removal volume of the conical cutter are higher than those of the cylindrical cutter when assisted by impact force.
\end{abstract}

\section{Introduction}

In the process of oil and gas exploration, there are some problems such as low rate of penetration (ROP), short pure drilling time and long drilling cycle in hard rock, and abrasive formation with poor drillability. In view of the above problems, many indoor tests and field applications of a conical PDC cutter have been carried out, and good results have been achieved [1-5].

Durrand et al. [6] first carried out the research on the conical PDC cutter. The indoor test results show that the conical cutter has better friction resistance, impact resistance, and heat resistance than the cylindrical cutter. Field tests show that it is more suitable for hard rock with high WOB, larger rock debris, and lower crushing specific energy. Sun and Zou [7] have carried out laboratory experiments on the conical cutter. They found that when the inclination angle is $20-25^{\circ}$, the cutting force and specific energy are the minimum, and the crushing efficiency is at the highest. Azar et al. and German et al. $[3,8]$ applied the hybrid bit in high hardness carbonate rock formation, the footage increased by $29 \%-190 \%$, the ROP increased by $62 \%-157 \%$, and the weight on bit decreased by $26 \%$. Conical bit and hybrid bit have great potential and application prospects in prolonging bit life and improving ROP.

Impact force can restrain downhole vibration and improve bit life. Wang and Lehnhoff [9] used the finite element method to simulate the cutting formation process in the twodimensional rock cutting process. The material nonlinearity and geometric nonlinearity of rock are considered in the model. Han et al. [10] used the Mohr-Coulomb model to simulate the rock failure process assisted by the impact force, 
and the failure forms mainly include compression failure caused by stress wave, tensile failure caused by stress wave reflection, and fatigue failure caused by stress cyclic loading. Zhao et al. [11] obtained the relationship between the length of the intermediate crack, lateral crack, and radial crack and the amplitude of load and the impact velocity of load by studying the experiment of indenter pressing into rock. Zhao et al. [12] studied the characteristics of rock intrusion with a single cutter by rock breaking theory and experiment. Their results show that the increase of static pressure and impact energy can improve the cutting force and increase the rock removal volume. A certain preload can reduce the fracture toughness and hardness of the rock material and increase the crushing volume of rock. Increasing the impact frequency and reducing the impact distance can greatly improve the cutting depth in brittle and hard rock.

There are extensive research studies and applications of the impact force on the cylindrical PDC cutter [13-19]. There are also some experiments and field applications of the conical cutter $[7,20]$, but there is no research on the conical cutter and the cylindrical cutter cutting rock assisted by the impact force. Therefore, the research on the cutting rock law of conical and cylindrical cutters assisted by the impact force is beneficial to expand the application of the conical PDC cutter and further improve drilling efficiency. In this paper, based on the explicit dynamic method, the effect of the impact force on the conical cutter and cylindrical cutter cutting rock is studied with the Holmquist-Johnson-Cook model.

\section{Holmquist-Johnson-Cook Model}

In the case of high strain, high strain rate, and high pressure, Holmquist et al. [21] proposed the Holmquist-Johnson-Cook (HJC) model, and the equivalent strength equation of the model includes hydrostatic pressure, strain rate, and damage. The model is divided into three parts: the strength model, the damage model, and the constitutive model.

2.1. Strength Model. The strength model is described as follows:

$$
\sigma^{*}=\left[A(1-D)+B P^{* N}\right]\left(1+C \ln \dot{\varepsilon}^{*}\right),
$$

where the standard equivalent stress $\sigma^{*}=\sigma / f_{C}^{\prime}$ and $\sigma^{*}<S_{\max }$, $\sigma$ is the actual equivalent stress, $f_{C}^{\prime}$ is the quasistatic uniaxial compressive strength, and $S_{\max }$ is the upper limit of standard equivalent stress; $D$ is the damage $(0 \leq D \leq 1) ; P^{*}=P / f_{C}^{\prime}$ is the standard pressure ( $\mathrm{P}$ is the actual pressure); $\dot{\varepsilon}^{*}=\dot{\varepsilon} / \dot{\varepsilon}_{0}$ is the dimensionless strain rate ( $\dot{\varepsilon}$ is the actual strain rate, and $\dot{\varepsilon}_{0}=1 S^{-1}$ is the reference strain rate); $C$ is the strain rate coefficient; $A$ is the standard viscosity coefficient; $B$ is the standard pressure hardening coefficient; and $N$ is the pressure hardening index.

2.2. Damage Model. The damage model is expressed as follows:

$$
D=\sum \frac{\Delta \varepsilon_{p}+\Delta \mu_{p}}{\varepsilon_{p}^{f}+\mu_{p}^{f}},
$$

where $\varepsilon_{p}^{f}+\mu_{p}^{f}=D_{1}\left(P^{*}+T^{*}\right)^{D_{2}} \geq E F_{\min }, D_{1}$ and $D_{2}$ are the constants, $T^{*}=T / f_{C}^{\prime}, T$ is the maximum hydrostatic pressure that the material can withstand, and $E F_{\text {min }}$ is the plastic strain limit of the material failure. The damage is accumulated by an equivalent strain, which includes the equivalent plastic strain $\Delta \varepsilon_{p}$ and the plastic volume strain $\Delta \mu_{p}$

2.3. Constitutive Model. The constitutive model can be divided into three stages: linear elastic stage (equation (3)), transitional stage (equation (4)), and compaction stage (equation (5)).

$$
\begin{aligned}
& P=K \mu\left(-T(1-D) \leq P \leq P_{\text {crush }}\right), \\
& \left\{\begin{array}{l}
P=\frac{\left(\mu-\mu_{\text {crush }}\right)\left(P_{1}-P_{\text {crush }}\right)}{\left(\mu_{P}-\mu_{C}\right)}+P_{\text {crush }}(\text { uploading }) \\
P=P_{0}-\left[(1-F) K+F K_{\text {lock }}\right]\left(\mu_{0}-\mu\right)(\text { unloading })
\end{array}\left(P_{\text {crush }} \leq P \leq P_{\text {lock }}\right),\right. \\
& \left\{\begin{array}{l}
P=K_{1} \bar{\mu}+K_{2} \bar{\mu}^{2}+K_{3} \bar{\mu}^{3} \text { (uploading) } \\
P=K_{1} \bar{\mu} \text { (unloading) } \\
\bar{\mu}=\frac{\mu-\mu_{\text {lock }}}{1+\mu_{\text {lock }}}
\end{array}\left(P_{\text {lock }}<P\right) .\right.
\end{aligned}
$$

In the linear elastic stage, $P_{\text {Crush }}$ and $\mu_{\text {crush }}$ are the corresponding stress and volume strain in the uniaxial compression stress experiment.
In the transitional stage, the pores in the material are gradually squeezed out, resulting in plastic volumetric strain. In this stage, the unloading curve is different from the 
loading curve, and it will follow the interpolation path of the adjacent region.

In the compaction stage, the pores are completely extruded. Therefore, the standard volume strain rate $\mu$ can be calculated from the current density $\rho$ and the initial density $\rho_{0}, \mu=\rho / \rho_{0}-1$. The constants $\left(K_{1}, K_{2}\right.$, and $\left.K_{3}\right)$ are the material constants without porosity. The locked volume strain rate $\mu_{\text {lock }}$ can be calculated from the particle density $\rho_{\text {grain }}$ of the material, $\mu_{\text {lock }}=\rho_{\text {grain }} / \rho_{0^{-}}-1$.

\section{Numerical Model}

The cutting rock process of the conical cutter is simulated in this paper, and the effect of the impact force on the cutting process is studied. In simulations, assumptions are as follows: (1) the material of the cutter is rigid; (2) the rotary motion of the PDC cutter is simplified to a linear motion; and (3) the rock material has no initial confining pressure and initial damage. To improve the calculation speed, the symmetrical plane boundary condition is used to halve the model. The width, length, and height of the rock sample are $15 \mathrm{~mm}, 70 \mathrm{~mm}$, and $20 \mathrm{~mm}$, respectively. We use the hexahedral mesh for the rock sample, as shown in Figure 1. A fine mesh with an average element size of $0.20 \mathrm{~mm}$ is used for the top $10 \mathrm{~mm}$ of the sample, while a course with an average element size of $1 \mathrm{~mm}$ is used for the bottom $10 \mathrm{~mm}$ of the sample. The above physical model is meshes as shown in Figure 1, in which the cutter is a rigid material, and the rock material is the HJC model. The model parameters are listed in Table 1. To simulate the influence of bit inertia on the rock breaking process, the average value of bit mass on a single tooth is applied to a cutting tooth, which is $5 \mathrm{~kg}$.

The diameter of the conical cutter is $13 \mathrm{~mm}$, and the apex angle is $75^{\circ}$. The radius of the cone tip is $2 \mathrm{~mm}$. The diameter of the cylindrical cutter is $13 \mathrm{~mm}$, and the radius of the chamfered corner is $0.5 \mathrm{~mm}$. The geometric dimensioning of the cutter is shown in Figure 2, where $w$ is the WOB and $v$ is the cutting speed.

\section{Simulation Results and Analysis}

Due to the influence of bit inertia and bit rock contact stiffness, the impact force exerted on the bit cannot be directly transmitted to the bit rock contact surface. Therefore, the frequency and amplitude of the impact force are the important factors affecting the rock-breaking efficiency. To express the axial impact force, the WOB equation can be expressed as follows:where $k$ is the impact frequency, $p$ is the impact amplitude, and $w_{0}$ is the static value of WOB. The conical cutter and the cylindrical cutter were firstly used to simulate the process of cutting rock assisted by the impact force. The static WOB is $900 \mathrm{~N}$, the cutting speed is $0.8 \mathrm{~m} / \mathrm{s}$, the impact frequency is $20 \mathrm{~Hz}$, and the impact amplitude is $1000 \mathrm{~N}$. The equivalent stress cloud is shown in Figure 3, in which the PDC cutter is hidden. The unit of stress in the figure is MPa. The rock stress decay direction with the cylindrical tooth is perpendicular to the cutting tooth surface, and the maximum stress appears on the contact surface between the cylindrical cutter and rock. The equivalent stress of rock cutting by the conical tooth is mainly affected by the spherical cone, the attenuation direction is inclined downward, and the maximum stress only appears in the contact area between the spherical cone tip and rock. The equivalent stress of rock cutting by the conical cutter is mainly affected by the spherical cone tip; the stress decay direction is perpendicular to the sphere of the cone; the maximum stress of rock only appears in the contact area with the spherical cone.

$$
w=w_{0}+p(1+\sin 2 k \pi t),
$$

4.1. Influence of Impact Frequency. This section studies the influence of frequency of the impact force on rock cutting by the conical cutter and the cylindrical cutter. The impact amplitude is set to $1000 \mathrm{~N}$.

Figure 4 shows the effect of frequency of impact forces on the WOB frequency spectrum. In the WOB frequency spectrum of the cylindrical cutter, there is no significant dominant frequency when there is no impact. The dominant frequencies of WOB are $20 \mathrm{~Hz}$ and $40 \mathrm{~Hz}$ and the amplitudes are $620 \mathrm{~N}$ and $600 \mathrm{~N}$ when the frequencies of the impact force are $20 \mathrm{~Hz}$ and $40 \mathrm{~Hz}$, respectively. But there is no main frequency when the impact frequency reaches or even exceeds $60 \mathrm{~Hz}$. In the WOB frequency spectrum of the conical cutter, there is no significant dominant frequency when there is no impact. The dominant frequencies of WOB are $20 \mathrm{~Hz}$ and $40 \mathrm{~Hz}$ and the amplitudes are $680 \mathrm{~N}, 640 \mathrm{~N}$, and $420 \mathrm{~N}$, respectively, when the frequencies of the impact force are $20 \mathrm{~Hz}, 40 \mathrm{~Hz}$, and $60 \mathrm{~Hz}$. But there is no main frequency when the impact frequency reaches or even exceeds $60 \mathrm{~Hz}$. The comparison shows that the impact force has a more significant effect on the main frequency of the conical cutter. The impact at the dominant frequency will inevitably affect the WOB on the cutter.

Figure 5 shows the effect of the impact force frequency on the average WOB. When the impact frequency is $20 \mathrm{~Hz}$, the average WOB on the cylindrical cutter increases by $102 \%$ compared with that without impact, and the average WOB on the conical cutter increases by $82 \%$. As the impact frequency increases, the average WOB decreases rapidly. When frequencies are higher than $60 \mathrm{~Hz}$, the average $\mathrm{WOB}$ on the cylindrical cutter and that on the conical cutter are almost the same, increasing by $70 \%$ compared with those without the impact. Impact force has a greater impact on the dominant frequency of the conical cutter, resulting in a higher average WOB on the conical cutter.

Impact force affects the WOB and will inevitably affect the cutting depth. Figure 6 shows the cutting depth-time curves of the cylindrical cutter and conical cutter at different impact frequencies. When there is no impact, the cutting depth of the cylindrical cutter is more stable than the conical cutter. When the impact frequency is $20 \mathrm{~Hz}$ and $40 \mathrm{~Hz}$, the fluctuation of the cutting depth of the cylindrical cutter is very large, and the maximum value is $2 \mathrm{~mm}$. When the impact frequency is not less than $60 \mathrm{~Hz}$, the cutting depth of the cylindrical cutter is relatively stable, but it has a significant increase compared with that without impact.

When there is no impact, the cutting depth of the conical cutter fluctuates greatly. When impact frequency is $20 \mathrm{~Hz}$, the 


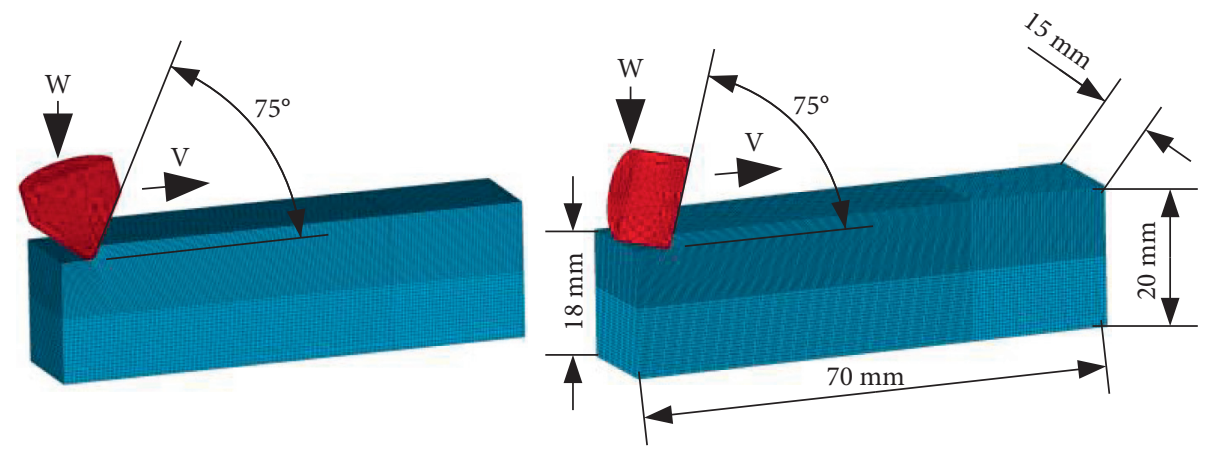

FIGURE 1: Finite element model of cutting rock.

TABle 1: Parameters of the finite element model.

\begin{tabular}{lc}
\hline Parameter/unit & Value \\
\hline$A$ & 0.79 \\
$B$ & 1.6 \\
$N$ & 0.61 \\
$C$ & 0.007 \\
$f_{c}^{\prime} / G P a$ & 0.048 \\
$S_{\max }$ & 7 \\
$D_{1}$ & 0.04 \\
$D_{2}$ & 1 \\
$E F_{\text {min }}$ & 0.01 \\
$P_{\text {crush }} / G P a$ & 0.016 \\
$\mu_{\text {crush }}$ & 0.001 \\
$K_{1} / G P a$ & 85 \\
$K_{2} / G P a$ & -171 \\
$K_{3} / G P a$ & 208 \\
$\mu_{\text {lock }}$ & 0.1 \\
$P_{\text {lock }} / G P a$ & 0.8 \\
$T / G P a$ & 0.004 \\
$G / G P a$ & 14.86 \\
$\rho / k g / m^{3}$ & 2440 \\
$J / K g \cdot K$ & 654 \\
\hline$A$ standard & .
\end{tabular}

$A$ : standard viscosity coefficient; $B$ : standard pressure hardening coefficient; $N$ : pressure hardening index; $C$ : strain rate coefficient; $f_{c}^{\prime}$ : quasi-static uniaxial compressive strength; Smax: the upper limit of standard equivalent stress; $D_{1}$ : constant; $D_{2}$ : constant; $\mathrm{EF}_{\text {min }}$ : plastic strain limit of material failure; $P_{\text {crush: }}$ stress in the uniaxial compression stress experiment; $\mu_{\text {crush }}$ : volume strain in the uniaxial compression stress experiment; $K_{1}, K_{2}$, and $K_{3}$ : material constant without porosity; $\mu_{\text {lock }}$ locked volume strain rate; $P_{\text {lock: }}$ locked stress; $T$ : the maximum hydrostatic pressure that the material can withstand; $G$ : the shear modulus; $\rho$ : density of rock; and $J$ : specific heat capacity.

cutting depth fluctuation increases rapidly. When the impact frequency increases to $40 \mathrm{~Hz}$, the fluctuation of cutting depth is $1.5 \mathrm{~mm}$. When the impact frequency exceeds $40 \mathrm{~Hz}$, the cutting depth fluctuation decreases. The fluctuation of cutting depth of the cylindrical teeth is larger, but the curve of the conical cutter is smoother.

Figure 7 shows the average cutting depth and removal volume of the cylindrical cutter and the conical cutter at different impact frequencies. For the cylindrical cutter, the average cutting depth without impact is $1.57 \mathrm{~mm}$ and the removal volume is $0.563 \mathrm{~g}$. When the impact frequency is $20 \mathrm{~Hz}$, the average cutting depth is $3.2 \mathrm{~mm}$ and the removal volume is $1.48 \mathrm{~g}$, which increase by $105 \%$ and $162 \%$, respectively. When the impact frequency increases to $60 \mathrm{~Hz}$, the average cutting depth and removal volume decrease to $2.8 \mathrm{~mm}$ and $1.28 \mathrm{~g}$, respectively. When the impact frequency reaches $60 \mathrm{~Hz}$, the average cutting depth and removal volume are $2.7 \mathrm{~mm}$ and $1.2 \mathrm{~g}$, respectively.

For the conical cutter, the average cutting depth is $1.7 \mathrm{~mm}$ and the removal volume is $0.28 \mathrm{~g}$ when there is no impact force. When the impact frequency is $20 \mathrm{~Hz}$, the average cutting depth and removal volume are $2.8 \mathrm{~mm}$ and $0.61 \mathrm{~g}$, respectively, increasing by $64 \%$ and $117 \%$. When the impact frequency increases to $40 \mathrm{~Hz}$, the average cutting depth and removal volume decrease to $2.5 \mathrm{~mm}$ and $0.53 \mathrm{~g}$. When the impact frequency is $60 \mathrm{~Hz}$, the average cutting depth and removal volume are $2.46 \mathrm{~mm}$ and $0.5 \mathrm{~g}$, respectively, which increase by $44 \%$ and $78 \%$ compared with those without the impact force. The impact frequency continues to increase, while the average cutting depth and removal volume remain unchanged.

Therefore, when the amplitude of the impact force is given, there is an upper threshold for the impact frequency. In this paper, the frequency threshold of the cylindrical cutter and the conical cutter is $60 \mathrm{~Hz}$. The impact force has two components: the fluctuation component and the mean component of the impact force. The mean component increases the average WOB, and the fluctuation component leads to the impact fragmentation of rock. The fluctuation component of the impact force acts on cutting teeth and rock, and the inertia of cutter also occupies a part of the fluctuation component. The higher the frequency is, the more fluctuation component occupied by the inertia of cutter. Impact fragmentation of rock occurs only when the fluctuation component applied to the rock is greater than a certain value. When the impact amplitude is constant and the frequency increases, the fluctuation component of the impact force becomes smaller, and the fluctuation component occupied by the inertia of cutter increases. It results in a lower fluctuation component acting on the rock. With the increase of frequency, the impact fragmentation will disappear when the impact component on rock decreases to a certain value.

4.2. Influence of Impact Amplitude. To study the effect of impact amplitude on the rock breaking process of high and low-frequency impact forces, the rock breaking process of impact forces at $20 \mathrm{~Hz}$ and $100 \mathrm{~Hz}$ with different impact amplitudes was simulated.

Figure 8 shows the effect of the impact amplitude on the WOB frequency spectrum. When the cylindrical cutter is assisted by the impact force at $20 \mathrm{~Hz}$, there is no dominant 


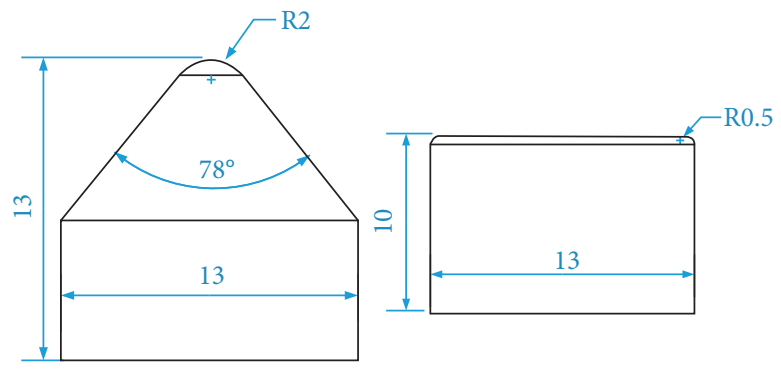

Figure 2: The geometric dimensioning of the cutter.

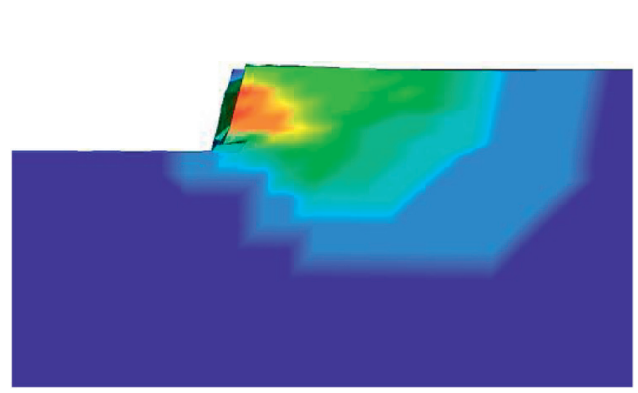

Cylindrical Cutter

$\left.\begin{array}{c}\text { Effective Stress } \\ 2.643 \mathrm{e}+02 \\ 2.379 \mathrm{e}+02 \\ 2.115 \mathrm{e}+02 \\ 1.850 \mathrm{e}+02 \\ 1.586 \mathrm{e}+02 \\ 1.322 \mathrm{e}+02 \\ 1.057 \mathrm{e}+02 \\ 7.930 \mathrm{e}+01 \\ 5.287 \mathrm{e}+01 \\ 2.644 \mathrm{e}+01 \\ 6.217 \mathrm{e}-03\end{array}\right]$

Figure 3: Equivalent stress cloud.
Effective Stress

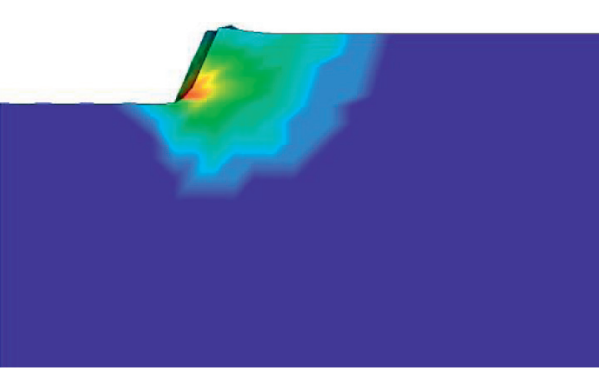

Conical Cutter
$2.619 \mathrm{e}+02$

$2.357 \mathrm{e}+02$ $2.095 \mathrm{e}+02$

$1.833 \mathrm{e}+02$

$1.571 \mathrm{e}+02$

$1.310 \mathrm{e}+02$

$1.048 \mathrm{e}+02$

$7.857 \mathrm{e}+01$

$5.238 \mathrm{e}+01$

$2.619 \mathrm{e}+01$

$0.000 \mathrm{e}+00$

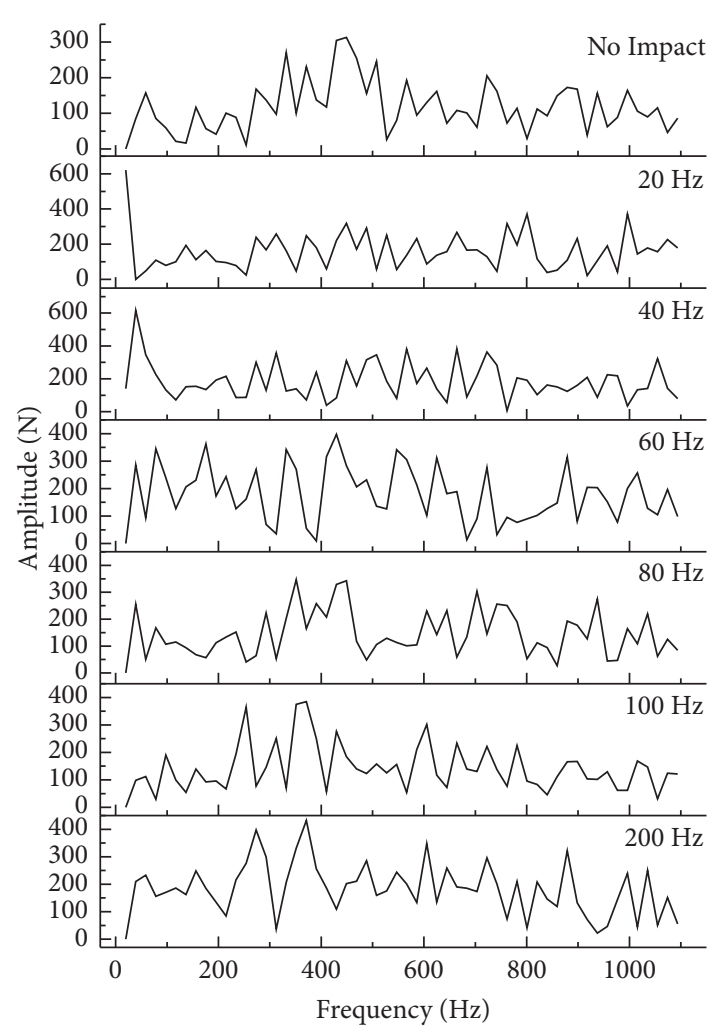

Cylindrical Cutter

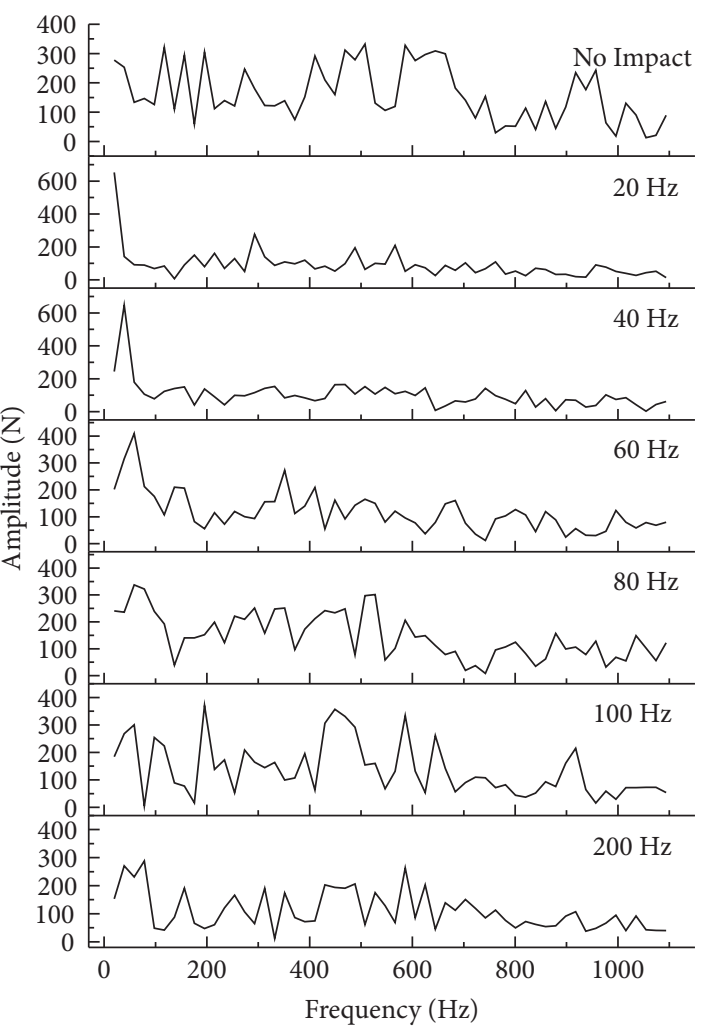

Conical Cutter

Figure 4: WOB frequency spectrum. 


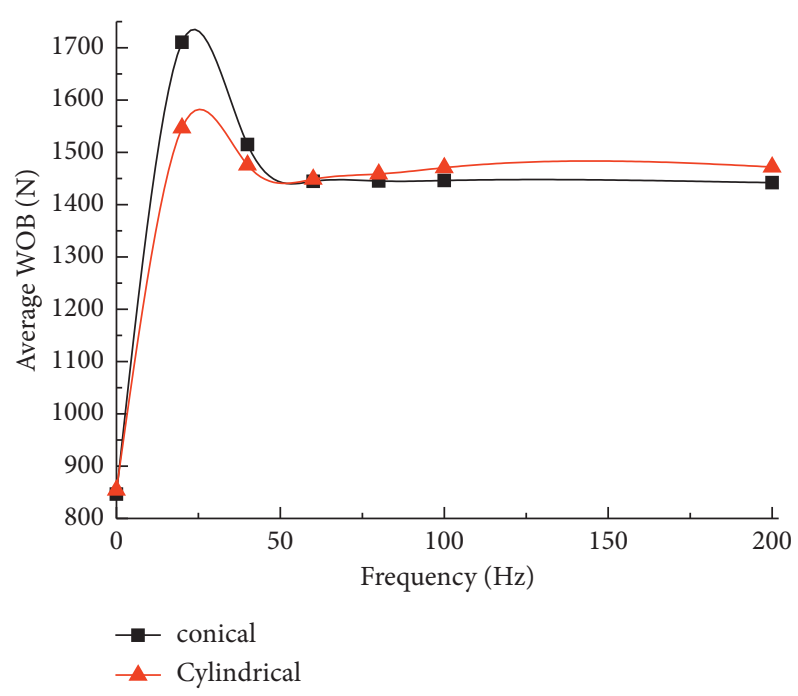

FIgURE 5: The effect of impact frequency on average WOB.

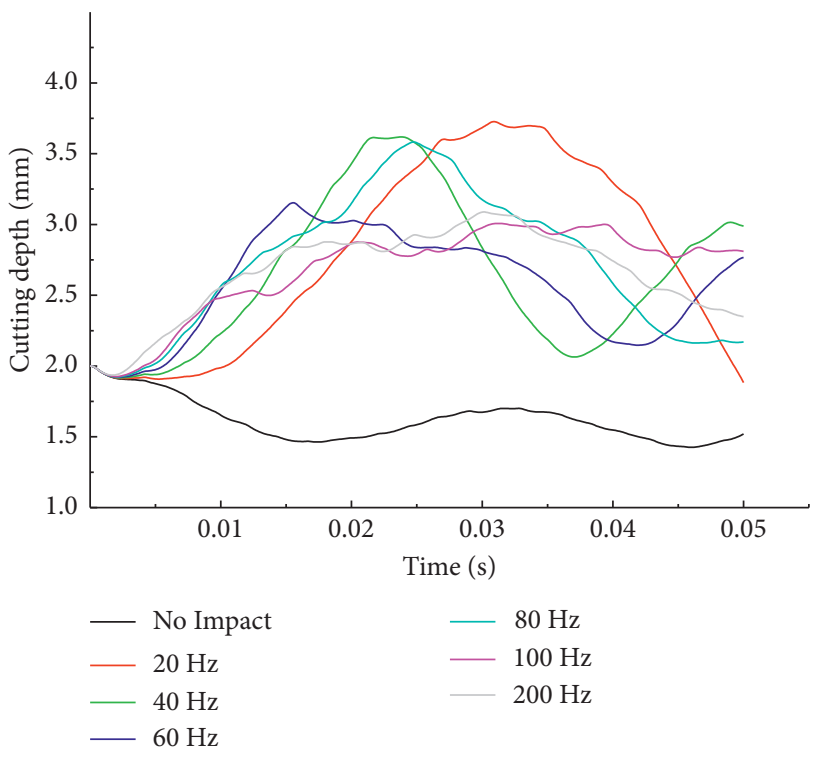

Cylindrical Cutter

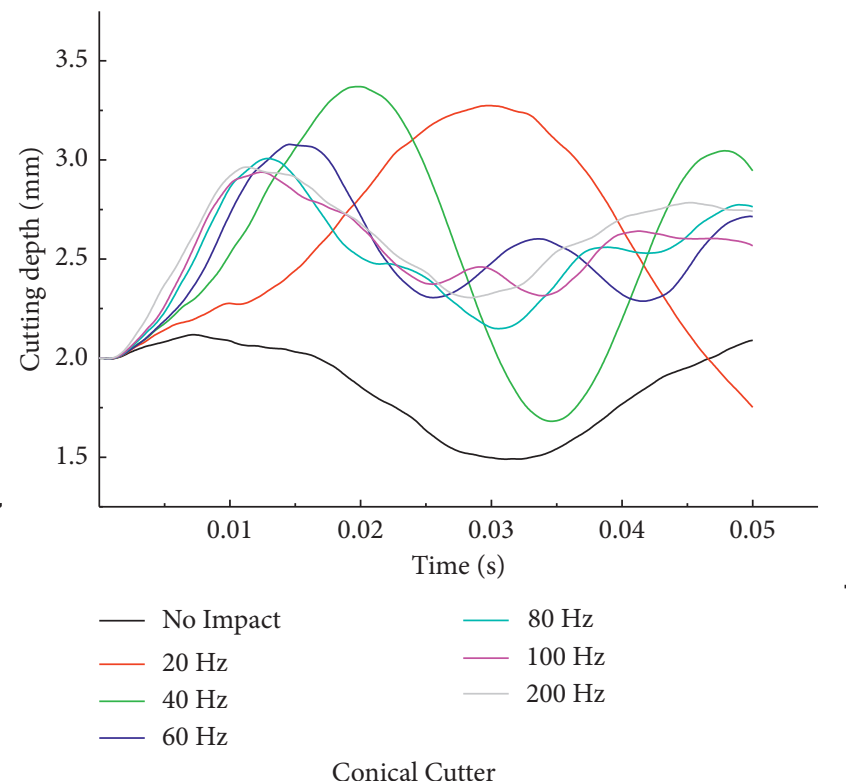

Conical Cutter

Figure 6: Cutting depth-time curve.

frequency if the impact amplitude is less than $600 \mathrm{~N}$. When the amplitude of the impact force increases to $800 \mathrm{~N}, 20 \mathrm{~Hz}$ becomes the dominant frequency, and the amplitude at the dominant frequency is $450 \mathrm{~N}$. When the impact amplitude is $1000 \mathrm{~N}$, the main frequency is $20 \mathrm{~Hz}$ and the amplitude increases to $600 \mathrm{~N}$. There is no dominant frequency when the frequency of impact force is $100 \mathrm{~Hz}$.

When the conical cutter is assisted by the impact force at $20 \mathrm{~Hz}$, there is no dominant frequency in the WOB frequency spectrum if the impact amplitude is less than $400 \mathrm{~N}$. When the amplitudes of impact force are $600 \mathrm{~N}, 800 \mathrm{~N}$, and $1000 \mathrm{~N}$, the dominant frequency is $20 \mathrm{~Hz}$ and the amplitudes at $20 \mathrm{~Hz}$ are $270 \mathrm{~N}, 450 \mathrm{~N}$, and $600 \mathrm{~N}$, respectively. WOB at $100 \mathrm{~Hz}$ impact force always has no dominant frequency.
There is no dominant frequency when the frequency of impact force is $100 \mathrm{~Hz}$.

The dominant frequency of the cylindrical cutter and the conical cutter only appears when the amplitude of impact force is higher than the threshold. The thresholds for the cylindrical cutter and the conical cutter are $600 \mathrm{~N}$ and $400 \mathrm{~N}$, respectively.

The average WOB curves for the cylindrical cutter and the conical cutter assisted by the impact force are shown in Figure 9. When the cylindrical cutter is assisted by the impact force at $100 \mathrm{~Hz}$, the average WOB increases linearly if the amplitude of the impact force is between 0 and $400 \mathrm{~N}$. When the impact amplitude exceeds $400 \mathrm{~N}$, the growth rate of average WOB decreases with the increase of the impact 


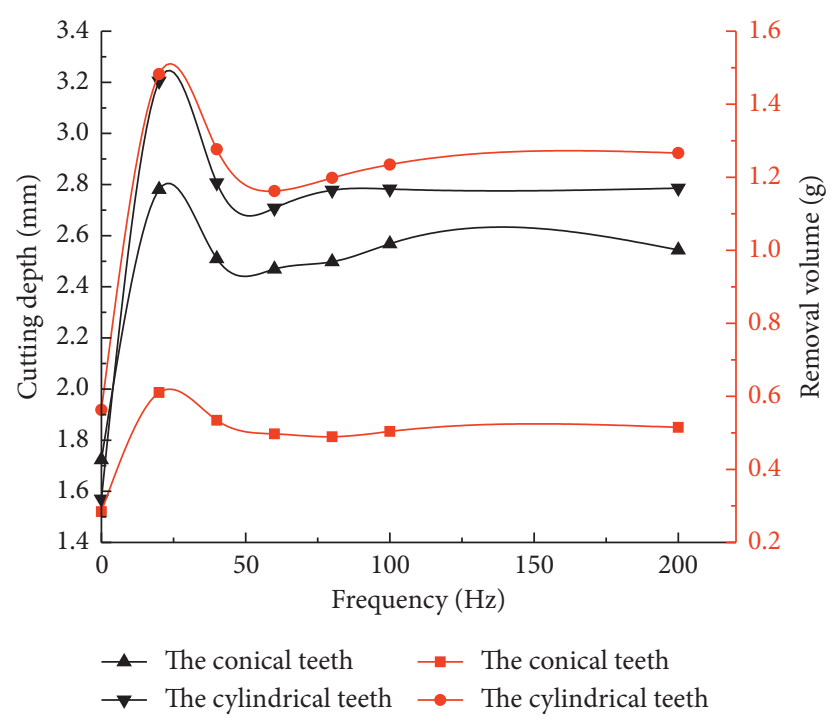

Figure 7: Cutting depth and removal volume.

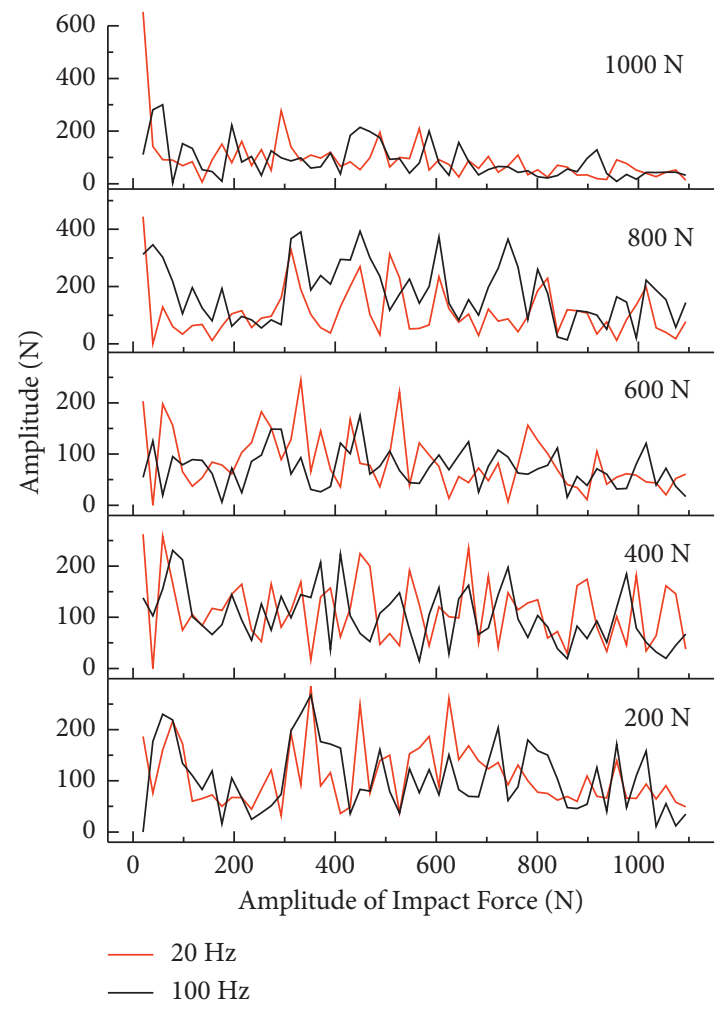

Cylindrical Cutter

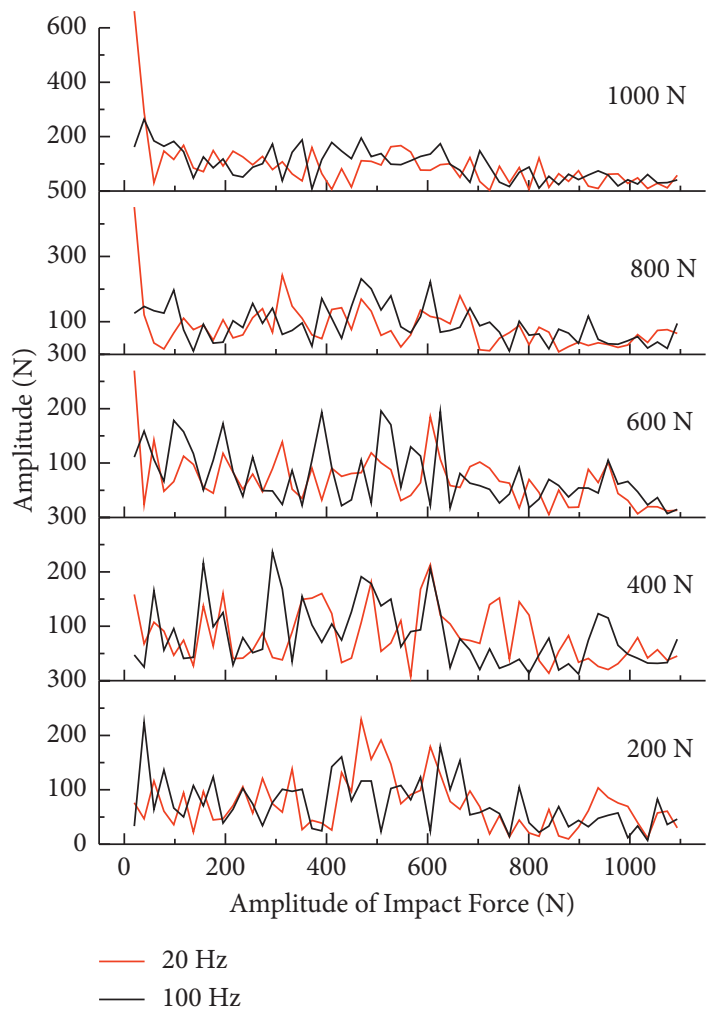

Conical Cutter

Figure 8: WOB frequency spectrum.

amplitude. When the impact frequency is $20 \mathrm{~Hz}$ and the impact amplitude is $0-400 \mathrm{~N}$, the average WOB increases linearly. When the impact amplitude is $400-1000 \mathrm{~N}$, the average WOB increases linearly with the increase of the impact amplitude, but the growth rate becomes higher. When the impact amplitude is $1000 \mathrm{~N}$, the average WOB is $1540 \mathrm{~N}$ if the impact frequency is $20 \mathrm{~Hz}$, and the average
WOB is $1350 \mathrm{~N}$ if the impact frequency is $100 \mathrm{~Hz}$. The former is $14 \%$ higher than the latter.

When the impact amplitude is $0-200 \mathrm{~N}$, the average WOB of the conical cutter at $20 \mathrm{~Hz}$ is the same as that at $100 \mathrm{~Hz}$. When the impact amplitude is greater than $200 \mathrm{~N}$, the average WOB increases almost linearly, but the growth rate of the former is larger. When the impact amplitude is 


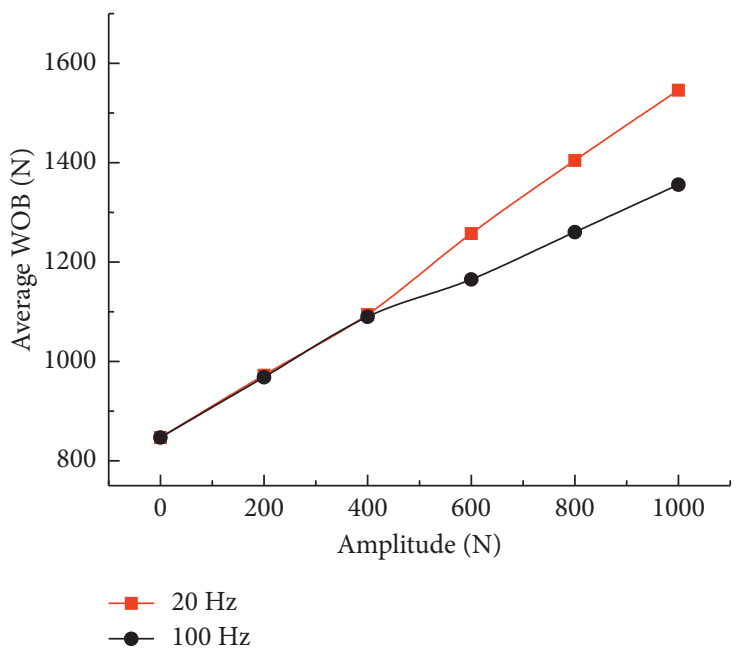

Cylindrical Cutter

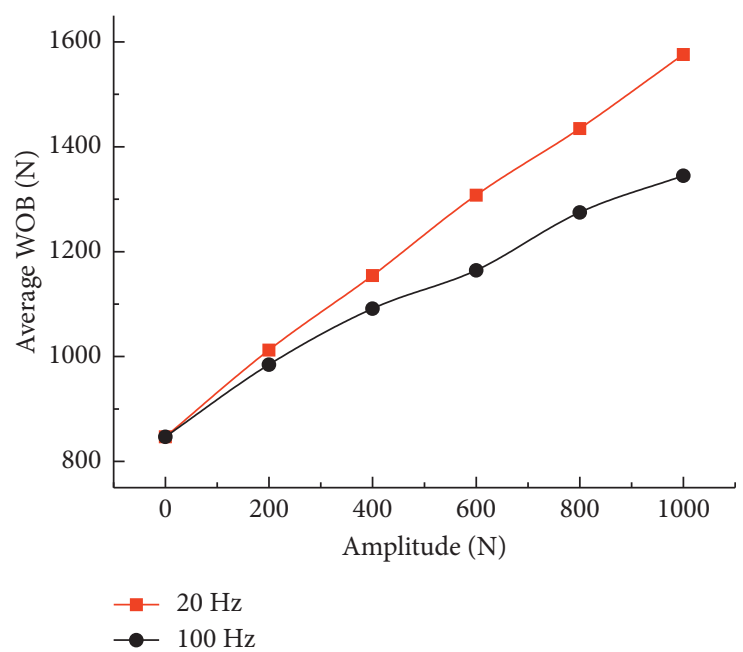

Conical Cutter

Figure 9: The effect of impact amplitude on average WOB.
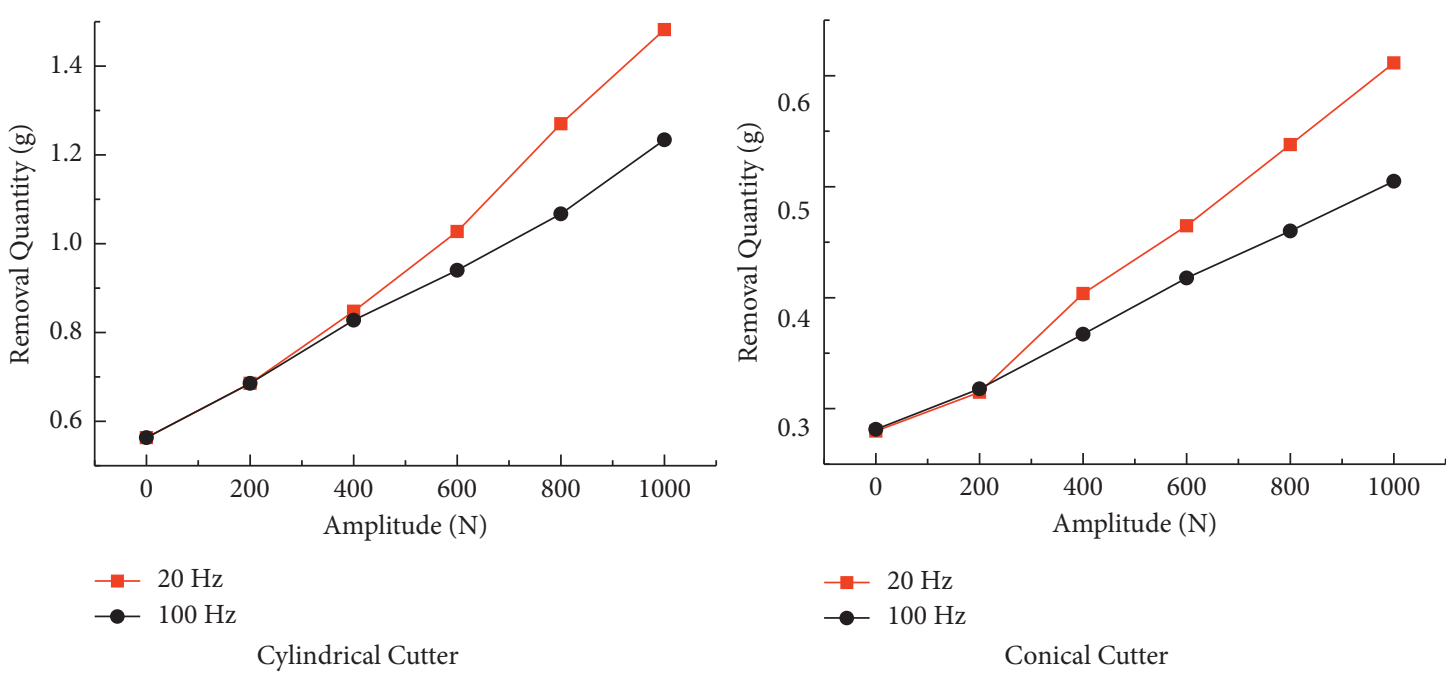

FIGURE 10: The effect of impact amplitude on removal volume.

$1000 \mathrm{~N}$, the average WOB is $1570 \mathrm{~N}$ if the impact frequency is $20 \mathrm{~Hz}$, and that is $1340 \mathrm{~N}$ if the impact frequency is $100 \mathrm{~Hz}$. The former is $17 \%$ higher than the latter.

Figure 10 shows the effect of the impact amplitude on removal volume. When the amplitude of the impact force is $0-400 \mathrm{~N}$, the removal volume at $20 \mathrm{~Hz}$ is the same as that at $100 \mathrm{~Hz}$ and increases linearly with the increase of the impact amplitude. When the amplitude of the impact force exceeds $400 \mathrm{~N}$ and the impact force is at $20 \mathrm{~Hz}$, the removal volume of the cylindrical cutter increases linearly and the growth rate is higher; but when the impact force is at $100 \mathrm{~Hz}$, the removal volume of the cylindrical cutter decreases. When the impact force is $1000 \mathrm{~N}$ and impact frequency is $20 \mathrm{~Hz}$ and $100 \mathrm{~Hz}$, the removal volume is $1.48 \mathrm{~g}$ and $1.23 \mathrm{~g}$, respectively. The former is $20 \%$ higher than the latter.

When the amplitude of the impact force is $0-200 \mathrm{~N}$ and impact frequency is $20 \mathrm{~Hz}$ and $100 \mathrm{~Hz}$, respectively, the removal volume of the conical cutter is the same. When the impact amplitude is greater than $200 \mathrm{~N}$, there is a linear relationship between the removal volume of the conical cutter and the impact amplitude. But the growth rate of the removal volume is greater when the impact frequency is $20 \mathrm{~Hz}$. When the impact amplitude is $1000 \mathrm{~N}$ and the frequency is $20 \mathrm{~Hz}$ and $100 \mathrm{~Hz}$, the removal volume is $0.61 \mathrm{~g}$ and $0.50 \mathrm{~g}$, respectively, and the former is $22 \%$ higher than the latter.

\section{Conclusion}

This paper identifies the main effects of the impact force on the rock-breaking process of the conical PDC cutter. The research points out that there is an upper threshold for the impact frequency and a lower threshold for the impact amplitude. The frequency threshold of both cylindrical cutter and conical cutter is $60 \mathrm{~Hz}$, and their impact amplitude threshold is $400 \mathrm{~N}$ and $200 \mathrm{~N}$, respectively. 
(1) When the impact frequency is lower than the threshold frequency, the impact force leads to a large peak value at the impact frequency in the WOB frequency spectrum, and the average WOB and removal volume increase significantly. But with the increase of impact frequency, the removal volume decreases rapidly.

(2) When the impact frequency is higher than the threshold, the peak value in the WOB frequency diagram decreases greatly, and the average WOB remains unchanged.

(3) When the impact amplitude is higher than the threshold value, the peak value in the frequency spectrum is the impact frequency.

(4) Although the cutting depth and removal volume of the conical cutter are lower than those of the cylindrical cutter, the amplifications of cutting depth and removal volume of the conical cutter are higher than those of the cylindrical cutter.

\section{Data Availability}

The raw data can be provided if requested.

\section{Conflicts of Interest}

The authors declare that they have no conflicts of interest.

\section{Acknowledgments}

This work was sponsored by the Major Science and Technology Project of the CNPC under Grant ZD2019-183-005.

\section{References}

[1] Y. Sun, D. Zou, Y. Guo, C. Xiuping, and Yi Yang, "Design and field application of plow-cutting PDC bit," Oil Drilling \& Production Technology, vol. 38, no. 1, pp. 53-56, 2016.

[2] Y. B. Benalouane, S. Mokrani, S. Ziani, and Z. Djamel, "Impregnated bits design and optimization: an iterative method for improving drilling performances. case study: hassi messaoud cambrian reservoir in Algeria," in Proceedings of the SPE/IADC Middle East Drilling Technology Conference and Exhibition, 2011.

[3] M. Azar, A. White, S. Segal, and S. Velvaluri, "Pointing towards improved PDC bit performance: innovative conical shaped polycrystalline diamond element achieves higher ROP and total footage," in Proceedings of the SPE/IADC Drilling Conference, 2013.

[4] R. Hempton, C. Copeland, G. Cox, and C. Faught, "Innovative conical diamond element bits drill back-to-back tight curves in one run, improving economics while reducing risk in avalon shale play, New Mexico," in Proceedings of the SPE Liquids-Rich Basins Conference-North America, 2015.

[5] V. Radhakrishnan, A. Chuttani, F. Anggrani, and H. Nan, "Conical diamond element technology delivers step change in directional drilling performance," in Proceedings of the IADC/ SPE Asia Pacific Drilling Technology Conference, 2016.

[6] C. Durrand, M. Skeem, and D. Hall, "Thick PDC, shaped cutters for geothermal drilling: a fixed cutter solution for a roller cone drilling environment," in Proceedings of the 44th
US Rock Mechanics Symposium and 5th US-Canada Rock Mechanics Symposium, American Rock Mechanics Association, Salt Lake City, UT, USA, 2010.

[7] Y. X. Sun and D. Y. Zou, "Experimental study on force of stinger cutter breaking rock," Applied Mechanics and Materials, vol. 727-728, pp. 406-410, 2015.

[8] V. German, M. Pak, M. Azar, and S. Bits, "Conical diamond element bit sets new performance benchmarks drilling extremely hard carbonate/chert formations, perm region Russia," in Proceedings of the SPE/IADC Drilling Conference and Exhibition, 2015.

[9] J.-K. Wang and T. Lehnhoff, "Bit penetration into rock-a finite element study," in Proceedings of the International Journal of Rock Mechanics and Mining Sciences \& Geomechanics Abstracts, 1976.

[10] G. Han, M. Bruno, and M. B. Dusseault, "Dynamically modelling rock failure in percussion drilling; proceedings of the Alaska Rocks 2005," in Proceedings of the 40th US Symposium on Rock Mechanics (USRMS), American Rock Mechanics Association, Anchorage, AK, USA, June 2005.

[11] F. Zhao, X. Li, F. Tao, and S. Xie, "Theoretical analysis and experiments of rock fragmentation under coupling dynamic and static loads," Chinese Journal of Rock Mechanics and Engineering, vol. 24, no. 8, pp. 1315-1320, 2005.

[12] F. Zhao, X. Li, and F. Tao, "Research on experiments of brittle rock fragmentation by combined dynamic and static loads," Rock and Soil Mechanics, vol. 26, no. 7, pp. 1038-1042, 2005.

[13] X. Zhu, H. Luo, and Y. Jia, "Numerical analysis of air hammer bit drilling based on rock fatigue model," Chinese Journal of Rock Mechanics and Engineering, vol. 31, no. 4, pp. 754-761, 2012.

[14] T. Lin, Z. Lian, Y. Meng, and B. Yang, "Finite elements method study on dynamic rock breaking in air drilling," Chinese Journal of Rock Mechanics and Engineering, vol. 27, no. S2, pp. 3592-3596, 2008.

[15] Y. Jing, X. Yuan, L. Jiang, and H. Zhang, "Numerical simulation and field experimental study on rock breaking in high speed rotating percussion drilling," Journal of China University of Petroleum(Edition of Natural Science), vol. 43, no. 1, pp. 75-80, 2019.

[16] S. Ziani, S. Fetayah, A. Boudebza, B. Mohammed Miloud, B. Yacine, and M. Fatah, "Percussion performance drilling motor delivered extreme cost saving in hard and abrasive formation in Ahnet Basin, Algeria," in Proceedings of the IADC/SPE Drilling Conference and Exhibition, 2018.

[17] X. Zhu and J. Liu, "Rock breaking and ROP rising mechanism of rotary-percussive drilling technology," Acta Petrolei Sinica, vol. 39, no. 2, pp. 216-222, 2018.

[18] S. Li, W. Li and T. Yan, A study on the rock breaking mechanism of drill bits under combined loads and field applications," Journal of Vibration and Shock, vol. 36, no. 16, pp. 51-55+112, 2017.

[19] X. Zhu and W. Liu, "The rock breaking and ROP rising mechanism for single-tooth high-frequency torsional impact cutting," Acta Petrolei Sinica, vol. 38, no. 5, pp. 578-586, 2017.

[20] R. Brown and B. Meckfessel, Improving marcellus Shale Performance Using Pdc Bits with Optimized Torque Management Technology, Cutting Structure Aggressiveness and Unique Roller Cone Steel Tooth Cutting Structures, SPE Eastern Regional Meeting, OnePetro, 2010.

[21] T. J. Holmquist, G. R. Johnson, and W. H. Cook, "A computational constitutive model for concrete subjected to large strains, high strain rates,and high pressures," in Proceedings of the14th Int symposium on ballistics, pp. 561-600, Quebec city, Canada, 1993. 